\title{
Análise de itens sobre sistema monetário brasileiro na Provinha Brasil de Matemática à luz da Teoria dos Campos Conceituais
}

\author{
Analysis of items on brazilian monetary system in Provinha Brazil of \\ Mathematics in the light of the Theory of Conceptual Fields
}

\author{
Ivana Siqueira Caldeira ${ }^{1}$ \\ Vinicius Carvalho Beck ${ }^{2}$ \\ João Alberto da Silva ${ }^{3}$
}

\begin{abstract}
Resumo:O objetivo deste trabalho é discutir as relações que existem entre as categorias de problemas aditivos propostas por Gérard Vergnaud, autor da teoria dos campos conceituais, e os problemas que abordam o sistema monetário brasileiro na Provinha Brasil de Matemática. A metodologia utilizada para coleta e análise dos dados neste trabalho é a pesquisa documental. Ao analisar situações monetárias que abordam as relações entre cédulas e moedas na Provinha Brasil de Matemática, identificamos a presença de problemas que requerem a habilidade de quantificar, as noções de funcionamento do sistema de numeração decimal e a capacidade de agir em problemas de composição aditiva de medidas. Todos os problemas analisados envolvem apenas a composição aditiva de medidas. Alguns problemas exigem que a criança compreenda o fato de que "a cada cem centavos tem-se um real", e assumimos aqui a hipótese de que este é um conceito-em-ação necessário para o acerto em situações desse tipo. Propomos a investigação da existência deste invariante operatório como um problema de pesquisa de trabalhos futuros.
\end{abstract}

Palavras-chave: Provinha Brasil. Grandezas Monetárias. Estruturas Aditivas.

\begin{abstract}
The aim of this paper is to discuss the relationships that exist between the categories of additive problems proposed by Gérard Vergnaud, author of the theory of conceptual fields, and the problems they address monetary brazilian systemas in Provinha Brazil of Mathematics. The methodology used for data collection and analysis in this work is the documentary research. By analyzing monetary situations that address the relationships between ballots and coin came from Brazil, we identified the presence of problems that require the ability to quantify, the notions of decimal numbering system and the ability to act on problems of additive composition of measures. All analyzed problems involve only the additive composition measurements. Some problems require
\end{abstract}

\footnotetext{
${ }^{1}$ Professora do Instituto Federal de Educação, Ciência e Tecnologia Sulriograndense (Ifsul), Campus CAVG. Professora dos cursos de Pós-graduação da Faculdade SENAC Pelotas e UCPEL. E-mail: ivanacsiqueira@gmail.com

${ }^{2}$ Professor de Matemática do Instituto Federal Sul-rio-grandense (Câmpus CaVG) e da EAD na Universidade Federal de Pelotas Doutor pela Universidade Federal do Rio Grande. E-mail: viniciuscavg@ gmail.com

3 Pós-Doutorado em Educação Matemática pela Universidade Federal de Pernambuco. Doutorado em Educação pela Universidade Federal do Rio Grande do Sul-UFRGS, com doutorado-sanduíche na Universidade de Genebra. Professor Associado na Universidade Federal do Rio Grande-FURG. E-mail: joaopiaget@gmail.com
}

Tangram - Revista de Educação Matemática, Dourados - MS - v.2 n.14, pp. 21 - 38 (2018) 


\title{
Análise de itens sobre sistema monetário brasileiro na Provinha Brasil de Matemática à luz da Teoria dos Campos Conceituais
}

that the child understands the fact that "every hundred cents has a real", and we assume here that this is a concept-in-action required for the setting in such situations. We propose the existence of this operative invariant as a search problem of future research.

Keywords: From Brazil. Monetary Magnitudes. Aditive Structures.

\section{Apresentação do Estudo}

A matemática é vista ao longo da história como uma ciência necessária e útil em diversos campos dos saberes, principalmente, pelo o seu uso no cotidiano das pessoas e em suas práticas sociais. Visto isso, se torna uma disciplina obrigatória em todos os anos do Ensino Básico, começando na Educação Infantil, com o propósito de estimular e desenvolver o raciocínio lógico-matemático e também na resolução de problemas. Segundo Danyluk (2002, p.20),

\begin{abstract}
A alfabetização matemática diz respeito aos atos de aprender a ler e a escrever a linguagem matemática, usada nas séries iniciais da escolarização. Compreendo alfabetização matemática, portanto, como fenômeno que trata da compreensão, da interpretação e da comunicação dos conteúdos matemáticos ensinados na escola, tidos como iniciais para a construção do conhecimento matemático.
\end{abstract}

Percebe-se, então, que existe uma imensa necessidade de desenvolver as habilidades matemáticas, assim promovendo o letramento matemático durante este processo de escolarização, com objetivo de proporcionar aos alunos uma compreensão de mundo e capaz de atuar ativamente no mesmo.

Partindo dessa importância, é fundamental verificar se este conhecimento esta sendo garantido através de um sistema de avaliação. Segundo Castro (2000),

Um sistema nacional de avaliação em larga escala pode fornecer informações sobre a situação educacional de um país e servir como fundamentação para o planejamento, monitoramento e acompanhamento das políticas públicas, considerando o aprendizado dos alunos em relação aos conteúdos e habilidades estabelecidos no currículo.

Portanto, desde 2011 a Provinha Brasil de Matemática, é uma proposta do Ministério da Educação e elaborada pelo INEP, partindo da preocupação com a alfabetização em Matemática, com objetivo de melhorar processo de ensino e aprendizagem desta disciplina nos anos inicias, sendo um instrumento de avaliação para os alunos após a conclusão do $1^{\circ}$ ano de escolaridade no Ensino Fundamental, assim prevenindo o diagnóstico

Tangram - Revista de Educação Matemática, Dourados - MS - v.2 n.1, pp. 21 - 38 (2018) 


\section{Análise de itens sobre sistema monetário brasileiro na Provinha Brasil de Matemática à luz da Teoria dos Campos Conceituais}

tardio das carências acumuladas nesse processo.

Com base na Matriz de Referência de Avaliação, a Provinha Brasil de Matemática aborda quatro eixos do conhecimento, os quais contemplam os principais blocos de conteúdos presentes nos currículos escolares: Números e Operações, Geometria, Grandezas e Medidas e Tratamento da Informação.

Para fins desde estudo, abordaremos especificamente, o eixo de conteúdo que refere-se a Grandezas e Medidas, mais precisamente as abordagens em relação ao Sistema Monetário (descritor D5.2 da Matriz de Referência da Provinha Brasil de Matemática: "Identificar e relacionar cédulas e moedas"). Porém, é importante ressaltar que este eixo ainda se subdivide em compreensões sobre comprimento e a duração de intervalos de tempo.

Neste trabalho adotamos como referencial teórico os estudos sobre campos conceituais, desenvolvidos por Gérard Vergnaud (1985, 1990, 1997). Para Vergnaud, um conceito é uma síntese de situações, invariantes operatórios e representações em torno de uma ideia em comum, a qual dará significado ao conceito.

Vergnaud (1985) descreve minuciosamente as componentes de dois campos conceituais em particular: o campo das estruturas aditivas e o campo das estruturas multiplicativas. Uma das ideias centrais do trabalho de Vergnaud (1985) é a de que existe certa dependência entre operações consideradas antagônicas, como por exemplo, no caso da adição e da subtração.

O conceito de adição se desenvolve e se consolida após haver o desenvolvimento do conceito de subtração. Por isso, situações envolvendo estritamente adição são insuficientes para o entendimento do campo aditivo. É necessário que sejam apresentadas ao sujeito situações de subtração.

Problemas monetários, frequentemente envolvem operações aritméticas, tais como adição e subtração. Por isso, considerar os estudos sobre campos conceituais ao analisar problemas que abordam situações monetárias abre a possibilidade de uma discussão interessante em termos da aprendizagem de habilidades monetárias nos anos iniciais do Ensino Fundamental.

O objetivo deste trabalho é discutir as relações que existem entre as categorias de problemas aditivos propostas por Vergnaud (1985) e os problemas que abordam o sistema monetário brasileiro na Provinha Brasil de Matemática.

\section{Habilidades Financeiras na Provinha Brasil de Matemática}

Tangram - Revista de Educação Matemática, Dourados - MS - v.2 n.1, pp. 21 - 38 (2018) 


\section{Análise de itens sobre sistema monetário brasileiro na Provinha Brasil de Matemática à luz da Teoria dos Campos Conceituais}

A Provinha Brasil de Matemática é uma avaliação de larga escala brasileira que possui o objetivo de avaliar a qualidade da alfabetização matemática. O público alvo são crianças matriculadas no segundo ano do Ensino Fundamental. A forma escrita dos enunciados é fornecida apenas aos aplicadores. Os estudantes recebem uma folha com a ilustração em tamanho maior, a qual visualizam enquanto o enunciado é lido pelo aplicador.

A Provinha Brasil de Matemática é realizada desde o ano de 2011, sendo aplicada duas vezes por ano, respectivamente nos meses de maio e novembro. A intenção da realização da PBM é conhecer as habilidades matemáticas de crianças na faixa etária dos seis aos oito anos de idade. Os conteúdos estabelecidos para o Ensino Fundamental nos Parâmetros Curriculares Nacionais (PCN) são selecionados para identificados conhecimentos, competências, hábitos e valores socialmente relevantes ao mesmo tempo em que contribuem para o desenvolvimento intelectual do aluno, na construção e coordenação do pensamento lógico-matemático, da criatividade, da intuição, da capacidade de análise e de crítica para interpretação de fatos e fenômenos (Brasil, 1997).

O bloco que trata sobre Grandezas e Medidas têm forte relevância social e evidente caráter prático e utilitário, por ser conteúdo vinculado ao cotidiano do aluno (Brasil, 1997). De acordo com os PCN (Brasil, 1997, p.73), os objetivos do trabalho com Grandezas e Medidas para as séries iniciais (atualmente anos iniciais) do Ensino Fundamental são:

- Comparar grandezas de mesma natureza, por meio de estratégias pessoais e uso de instrumentos de medida conhecidos - fita métrica, balança, recipientes de um litro, etc; Identificar unidades de tempo — dia, semana, mês, bimestre, semestre, ano - e utilização de calendários;

- Reconhecer cédulas e moedas que circulam no Brasil e de possíveis trocas entre cédulas e moedas, em função de seus valores;

- Identificar os elementos necessários para comunicar o resultado de uma medição e produção de escritas que representem essa medição;

- Ler horas, comparando relógios digitais e de ponteiros.

As habilidades que tratam do domínio sobre o sistema monetário brasileiro, a partir da indicação da Matriz de Referência, organizem-se sobre a capacidade de identificar cédulas, moedas e suas trocas em um contexto cultural específico, especificamente, sobre o sistema corrente no país. Segundo Muniz, Batista e Silva (2008), a maior dificuldade dos estudantes se dá nas trocas entre as diferentes unidades.

O sistema monetário é um importante recurso didático para o ensino dos números racionais. Mesmo não sendo esse um dos objetivos do Ciclo de Alfabetização, o uso das trocas entre centavos e reais permite já construir noções sobre números e operações com

Tangram - Revista de Educação Matemática, Dourados - MS - v.2 n.1, pp. 21 - 38 (2018) 


\section{Análise de itens sobre sistema monetário brasileiro na Provinha Brasil de Matemática à luz da Teoria dos Campos Conceituais}

racionais.

A ideia de que quatro moedas de cinquenta centavos são equivalentes a uma cédula de dois reais, por exemplo, pode ser estranha se pensarmos que $50+50+50+50=200$, mas a cédula é de dois reais. Seria mais exato dizer que $0,5+0,5+0,5+0,5=2$, porém deste modo precisaríamos estar no contexto dos números decimais, que não figura entre os assuntos no Ciclo de Alfabetização.

Estas trocas correspondem mais especificamente à habilidade de relacionar cédulas e moedas na Matriz de Referência da Provinha Brasil de Matemática. É uma habilidade bastante sofisticada, tendo em vista que antecipa a noção de número decimal.

\section{O Campo Conceitual das Estruturas Aditivas}

O campo conceitual das estruturas aditivas compreende todas as situações que envolvem a operação de adição, desde as mais elementares, com número naturais em contextos concretos, até as operações mais complexas estritamente ligadas ao conhecimento matemático. Vergnaud categorizou e estudou as particularidades de cada um dos tipos de problemas que envolvem conceitos aditivos.

Vergnaud (1985) classifica todos os problemas considerados no campo conceitual aditivo em seis categorias: composição de medidas; transformação de medidas; relação entre medidas; composição de transformações; transformação de estados relativos; e composição de estados relativos. Só as três primeiras são abordadas nos anos inciais.

Exemplo 1 (Vergnaud, 1985, pág. 202): "Paulo tem 6 bolinhas de gude de vidro e 8 bolinhas de gude de metal. Ele tem em tudo 14 bolinhas". Este é um problema de composição aditiva de medidas, que pode ser representado, seguindo a proposta de Vergnaud, pelo diagrama da Figura 1.

Tangram - Revista de Educação Matemática, Dourados - MS - v.2 n.1, pp. 21 - 38 (2018) 


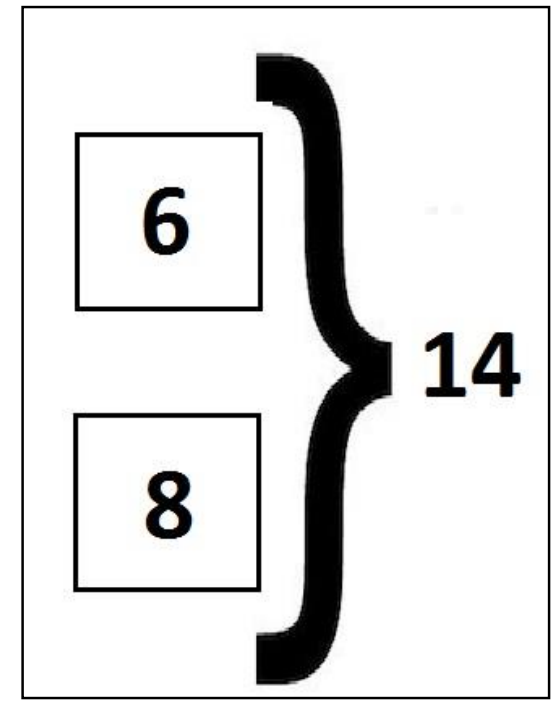

Figura 1 - Composição das Medidas do Exemplo 1

Fonte: Adaptado de Vergnaud (1985).

Na representação de Vergnaud, os retângulos representam números naturais e a chave representa a composição. No caso do exemplo 1, esta é a representação de que as medidas 6 e 8 são compostas para formar a medida 14 .

Exemplo 2: "Paulo tem 14 bolinhas de gude, algumas de vidro e outras de metal. Destas, 6 são de vidro. Ele tem 8 bolinhas de metal". Este é um problema de composição subtrativa de medidas, que também pode ser representado pelo diagrama da Figura 1.

Exemplo 3 (Vergnaud, 1985, pág. 202): "Paulo tinha 7 bolinhas de gude antes de jogar. Ganhou 4 bolinhas. Ele agora tem 11 bolinhas”. Este é um problema que pode ser definido como transformação de medidas, o qual pode ser representado pelo diagrama da Figura 2.

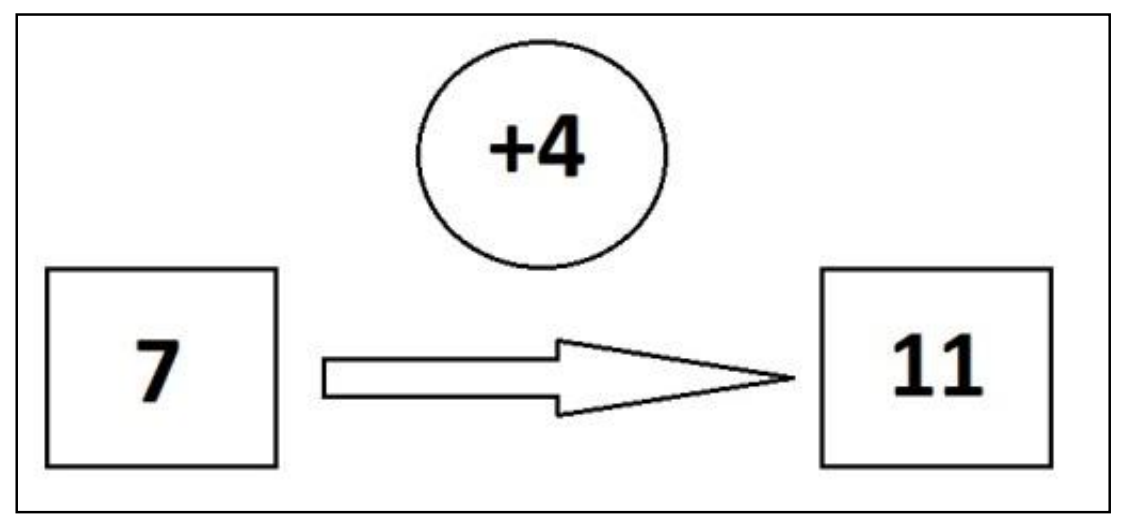

Figura 2 - Transformação das Medidas do Exemplo 3 Fonte: Adaptado de Vergnaud (1985).

Tangram - Revista de Educação Matemática, Dourados - MS - v.2 n.1, pp. 21 - 38 (2018) 


\section{Análise de itens sobre sistema monetário brasileiro na Provinha Brasil de Matemática à luz da Teoria dos Campos Conceituais}

$\mathrm{Na}$ representação de Vergnaud, os círculos representam os estados relativos (ou também os números relativos, ou seja, aqueles dotados de sinal) e as setas representam transformações. No caso do exemplo 3, está representado que a medida 7 foi transformada pelo número relativo +4 na medida 11 .

Exemplo 4 (Vergnaud, 1985, pág. 202): "Paulo tinha 7 bolinhas de gude antes de jogar. Perdeu 4 bolinhas. Ele agora tem 3 bolinhas". Este é outro problema de transformação de medidas, no qual se utiliza um número relativo negativo. Ele pode ser representado pelo diagrama da Figura 3.

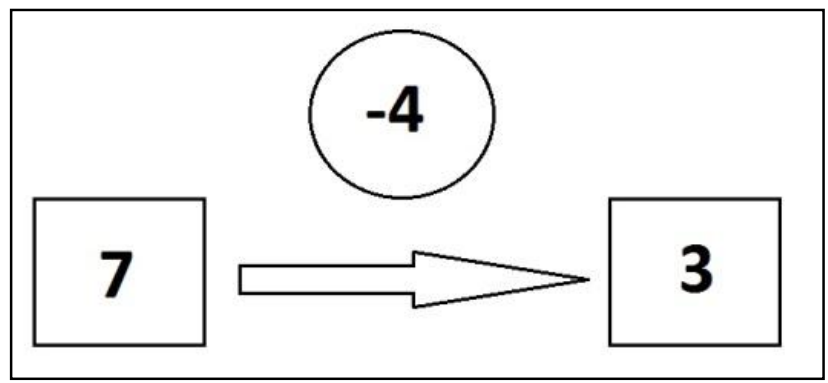

Figura 3 - Transformação das Medidas do Exemplo 4 Fonte: Adaptado de Vergnaud (1985)

Conforme ilustrado nos exemplos 3 e 4, as transformações podem ser positivas, quando envolvem estados relativos positivos, ou negativas, quando envolvem estados relativos negativos.

Exemplo 5 (Vergnaud, 1985, pág. 203): "Paulo tem 8 bolinhas de gude. Tiago tem 5 menos que Paulo. Então, Tiago tem 3". Este é um problema de relação entre medidas, que pode ser representado pelo diagrama da Figura 4.

Tangram - Revista de Educação Matemática, Dourados - MS - v.2 n.1, pp. 21 - 38 (2018) 


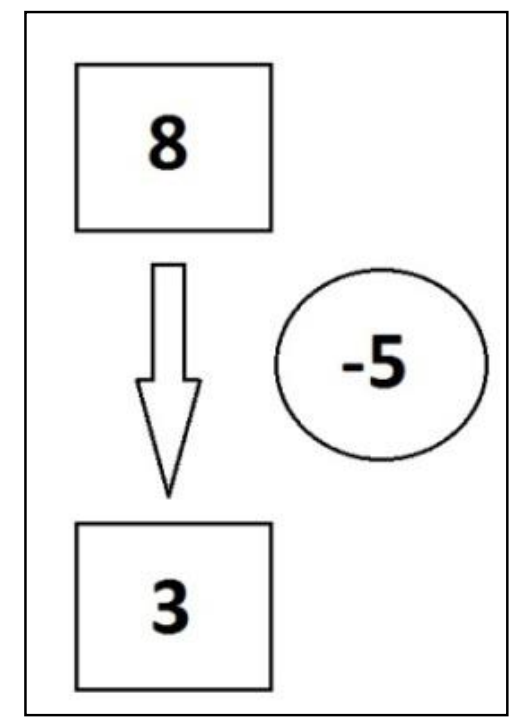

Figura 4 - Relação entre as Medidas do Exemplo 5

Fonte: Adaptado de Vergnaud (1985).

Nota-se que a representação das relações entre medidas é bastante semelhante a representação de transformações de medidas, no entanto, a diferença entre as duas representações está nas setas. Nas transformações, as setas são horizontais, enquanto nas relações as setas são verticais. No exemplo 5 , está representado que a medida procurada possui 5 estados relativos a menos que a medida dada, que é 8, resultando, portanto, em 3.

Assim como no caso das transformações, existem relações positivas e negativas. Vergnaud não apresenta na sequência uma relação positiva, embora as utilize em outros momentos de seu trabalho. Por isso, para complementar o entendimento das relações, apresentamos a seguir o exemplo 6, de uma relação positiva entre medidas, o qual foi elaborado a partir do exemplo 5.

Exemplo 6 (os autores): "Paulo tem 8 bolinhas de gude. Tiago tem 5 a mais que Paulo. Então, Tiago tem 13". Este é um problema de relação positiva entre medidas, que pode ser representado pelo diagrama da Figura 5.

Tangram - Revista de Educação Matemática, Dourados - MS - v.2 n.1, pp. 21 - 38 (2018) 


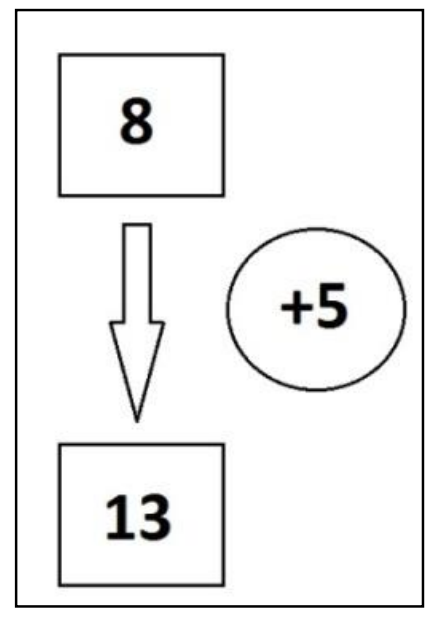

Figura 5 - Relação entre as Medidas do Exemplo 6 Fonte: Adaptado de Vergnaud (1985).

Os problemas de composição de medidas, transformação de medidas e relação entre medidas são os mais indicados para serem trabalhados no anos iniciais do Ensino Fundamental. As grandezas do sistema monetário brasileiro estão presentes na Provinha Brasil de Matemáticas na forma de cédulas e moedas, tendo como unidade de medida o real e o centavo.

\section{Procedimentos Metodológicos}

A metodologia utilizada para coleta e análise dos dados neste trabalho é a pesquisa documental. Segundo Cellard (2008, p.295),

[...] o documento escrito constitui uma fonte extremamente preciosa para todo pesquisador nas ciências sociais. Ele é, evidentemente, insubstituível em qualquer reconstituição referente a um passado relativamente distante, pois não é raro que ele represente a quase totalidade dos vestígios da atividade humana em determinadas épocas. Além disso, muito frequentemente, ele permanece como o único testemunho de atividades particulares ocorridas num passado recente.

Nesta modalidade, a proposta é produzir ou reelaborar conhecimentos e criar formas de entender e analisar os fenômenos. É importante que os fatos sejam mencionados, pois constituem os objetos da pesquisa. O pesquisador tem o dever de interpretá-los, sintetizando as informações, determinando as tendências e na medida do possível fazer a inferência. Segundo May (2004), “os documentos não existem isoladamente, mas precisam ser situados em uma estrutura teórica para que o seu conteúdo seja entendido".

Assim, este estudo tem por finalidade examinar o Programa de Avaliação da Alfabetização Inicial, tomando como objeto de análise as edições da Provinha Brasil de Tangram - Revista de Educação Matemática, Dourados - MS - v.2 n.1, pp. 21 - 38 (2018) 
Análise de itens sobre sistema monetário brasileiro na Provinha Brasil de Matemática à luz da Teoria dos Campos Conceituais

Matemática aplicadas até o ano de 2016, disponíveis na página eletrônica do Inep (2018).

Delimitamos o corpus de análise focando apenas nas questões referentes à habilidade de "relacionar cédulas e moedas". Não foram analisadas as questões que avaliam a habilidade de "identificar grandezas monetárias". Este recorte foi feito tendo em vista que as categorias de problemas aditivos propostas por Vergnaud (1985) se referem a problemas que envolvem as operações aritméticas de adição e subtração.

\section{Resultados e Discussão}

Desde 2011 foram aplicadas 15 testes da Provinha Brasil de Matemática. Ao longo de todas essas edições, constatamos que oito itens estavam diretamente ligados com a habilidade de relacionar cédulas e moedas. A seguir apresentamos uma análise desses oito itens, bem como a ligação de cada tipo de item com as categorias de problemas do campo aditivo propostas por Vergnaud (1985).

Nesta seção analisamos os itens da Provinha Brasil de Matemática que envolvem a habilidade de relacionar cédulas e moedas. Em tais problemas, para que seja possível o estudante inferir a equivalência entre valores, ele precisa ter desenvolvido ou estar desenvolvendo habilidade do campo conceitual aditivo.

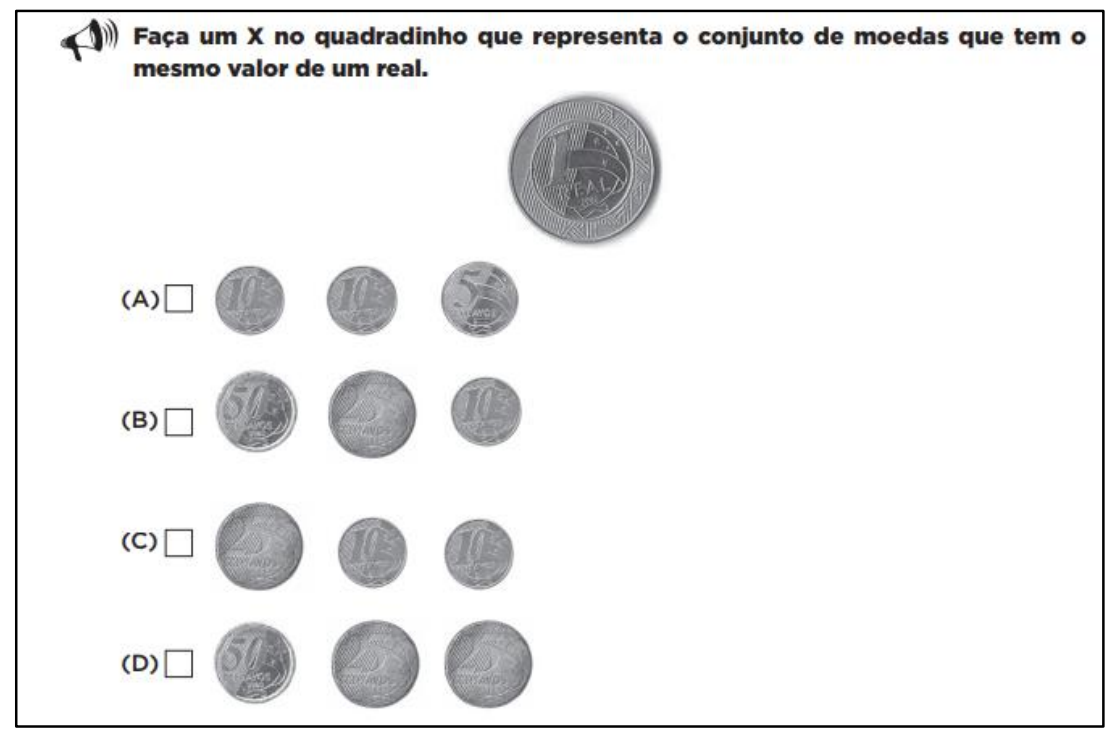

Figura 6 - Teste 1 da Provinha Brasil de 2011

Fonte: Adaptado de Inep (2018).

No problema da figura 6 percebe-se que há uma composição de medidas. As três moedas da opção D são compostas para tornarem-se uma moeda de um real. Notamos que Tangram - Revista de Educação Matemática, Dourados - MS - v.2 n.1, pp. 21 - 38 (2018) 


\section{Análise de itens sobre sistema monetário brasileiro na Provinha Brasil de Matemática à luz da Teoria dos Campos Conceituais}

$50+25+25=100$. A convenção de que 100 centavos equivalem a um real deve ser conhecida. Esta é uma noção que só pode ser compreendida após o contato com o sistema de numeração decimal, mais especificamente, com a noção de centena. Sendo assim, identificamos uma primeira relação de subordinação da compreensão das grandezas monetárias em relação ao campo das estruturas aditivas.

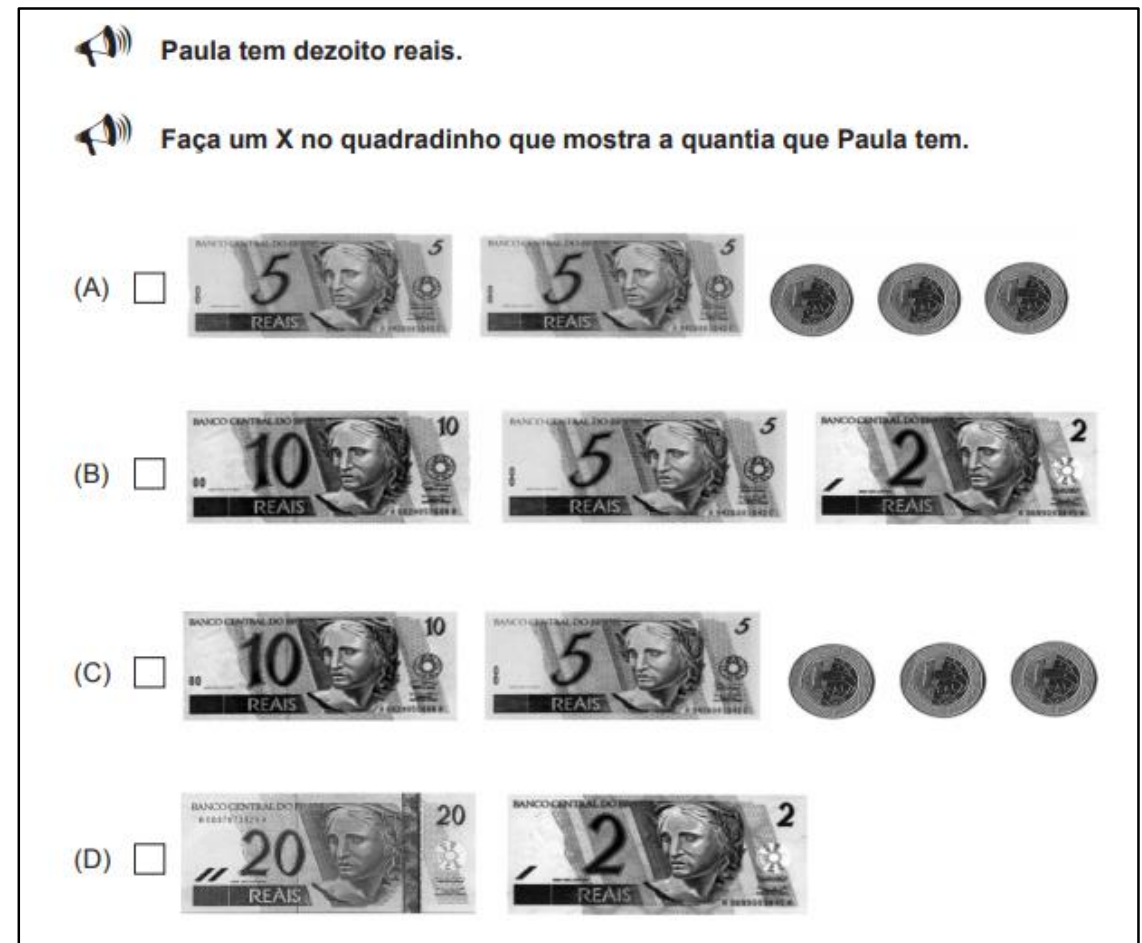

Figura 7 - Teste 2 da Provinha Brasil de 2012

Fonte: Adaptado de Inep (2018).

$\mathrm{Na}$ figura 7 notamos que este problema também apresenta características de composição de medidas, neste caso, até mais explícita, pois é preciso que a criança realize a operação mental de compor as notas e as moedas até resultar em dezoito reais. Não há uma exigência da compreensão de que uma nova unidade de medida seja convencionada, como no problema anterior, o que possibilita que a criança consiga agir mentalmente, mesmo sem conhecer profundamente o sistema de numeração decimal.

Tangram - Revista de Educação Matemática, Dourados - MS - v.2 n.1, pp. 21 - 38 (2018) 


\section{Análise de itens sobre sistema monetário brasileiro na Provinha Brasil de Matemática à luz da Teoria dos Campos Conceituais}

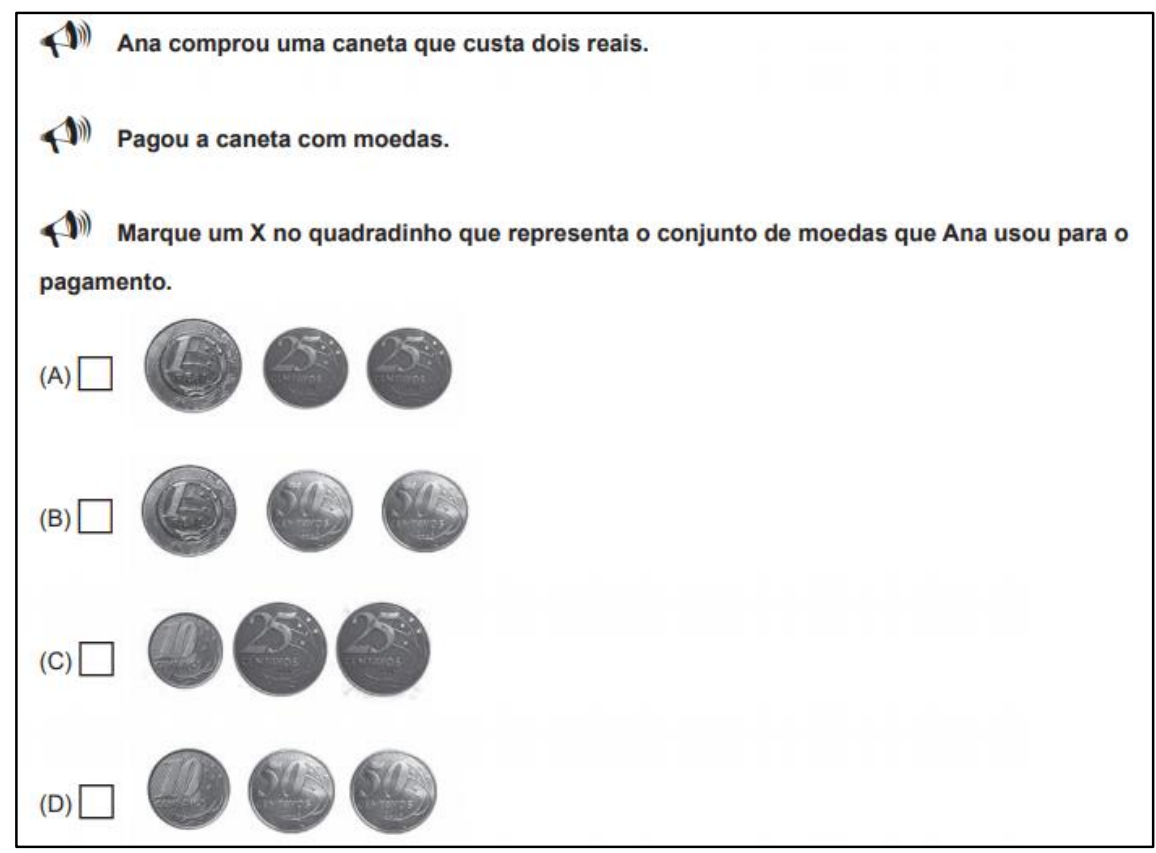

Figura 8 - Teste 2 da Provinha Brasil de 2013

Fonte: Adaptado de Inep (2018).

O problema da figura 8 também é um problema de composição de medidas. Neste problema, que envolve apenas moedas, as medidas reais e centavos são compostas para resultar em uma quantidade medida em reais, apenas. Exige um conhecimento da convenção "a cada cem centavos tem-se um real", e, por conseguinte, noções de funcionamento so sistema de numeração decimal.

Nas palavras de Vergnaud (1990), a convenção "a cada cem centavos tem-se um real" constitui um invariante operatório do tipo conceito-em-ação, que é um pressuposto adotado pelo sujeito para agir em situações que envolvem determinado conceito. Neste caso, o conceito de grandeza do sistema monetário brasileiro.

É importante salientar que, como esta é uma pesquisa documental, assumimos apenas como hipótese a possibilidade de uso deste conceito-em-ação, pois para que se pudesse constatar a existência de tal invariante operatório, teríamos que realizar uma pesquisa com sujeitos do Ciclo de Alfabetização, o que pode ser realizado em pesquisas futuras, as quais poderão tomar como hipótese inicial a análise proposta no presente trabalho.

Tangram - Revista de Educação Matemática, Dourados - MS - v.2 n.1, pp. 21 - 38 (2018) 


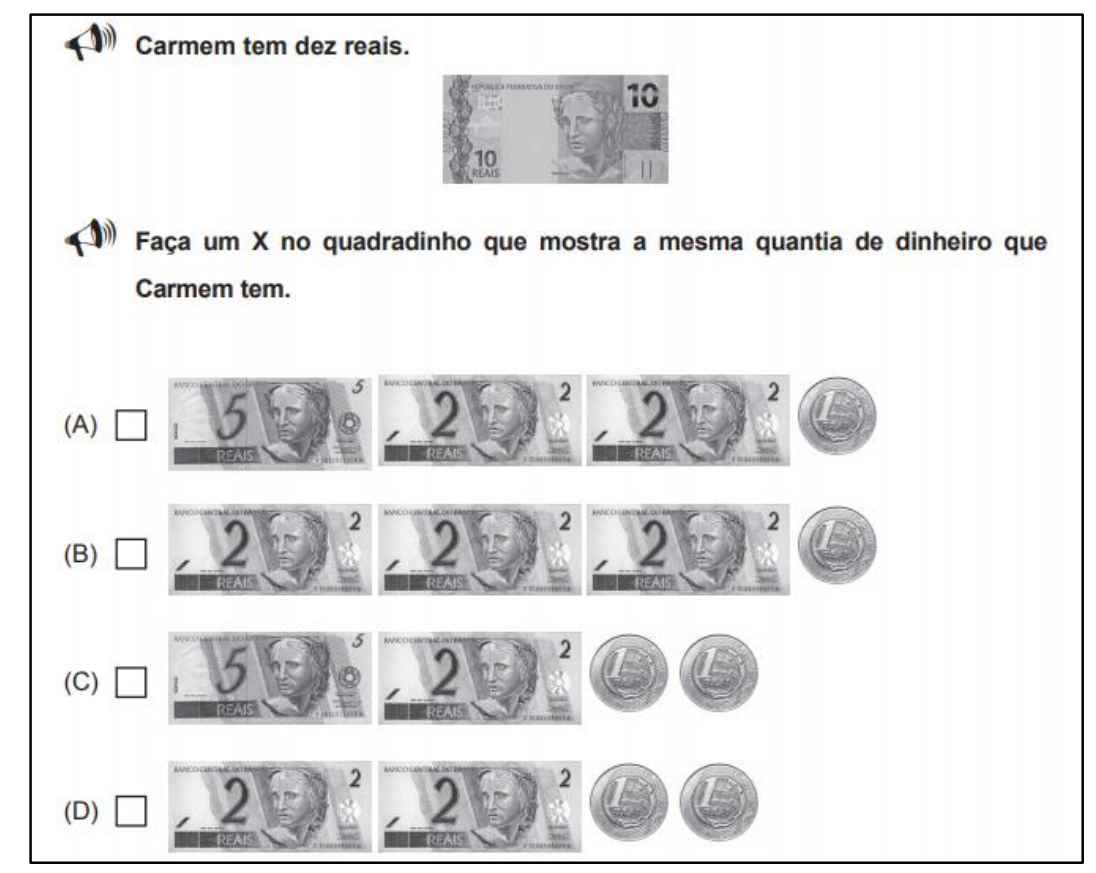

Figura 9 - Teste 2 da Provinha Brasil de 2014 Fonte: Adaptado de Inep (2018).

Na figura 9 observamos uma questão que também se trata de composição aditiva de medidas, envolvendo uma soma de cédulas e moedas para ter uma cédula como resultado. Não há necessidade de uso do conceito-em-ação "a cada cem centavos tem-se um real". 
Análise de itens sobre sistema monetário brasileiro na Provinha Brasil de Matemática à luz da Teoria dos Campos Conceituais

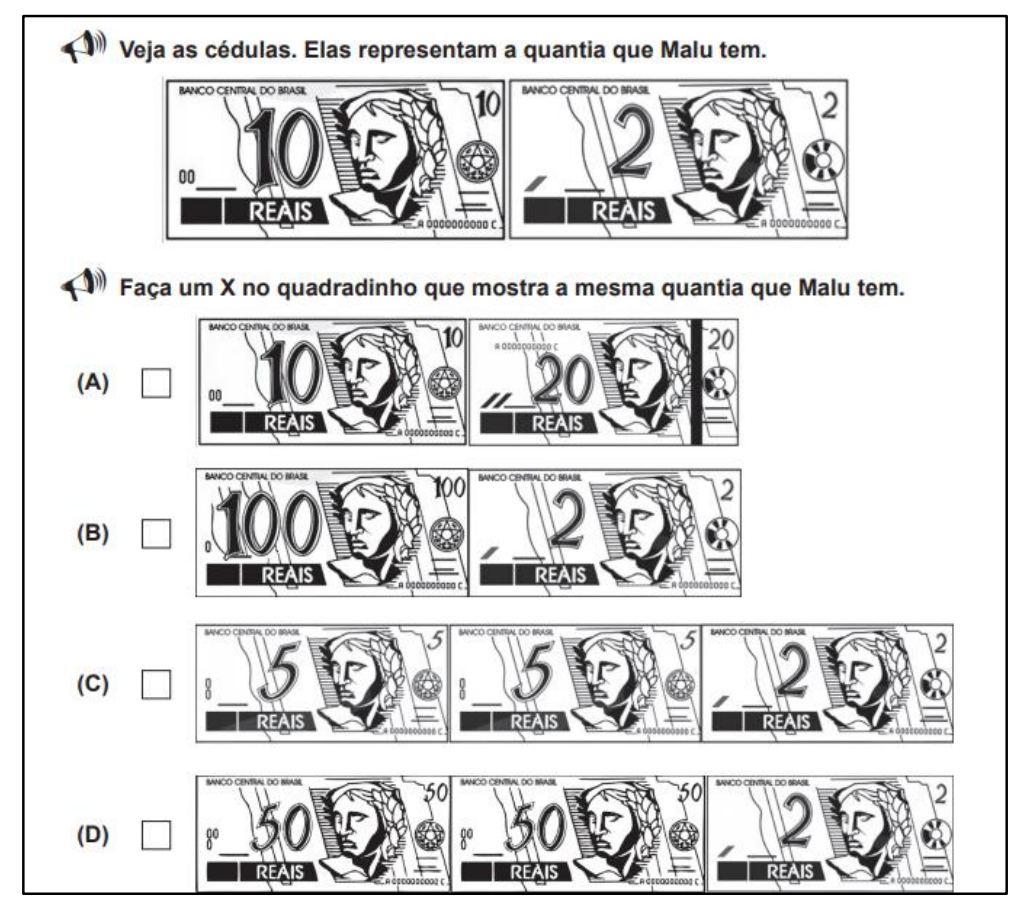

Figura 10 - Teste 1 da Provinha Brasil de 2015

Fonte: Adaptado de Inep (2018).

O problema da figura 10 se trata também de uma composição aditiva de medidas, sem a necessidade de uso do conceito-em-ação "a cada cem centavos tem-se um real". Este problema requer a habilidade de quantificar números naturais, isto é associar a quantidade ao numeral correspondente (KAMII, 1990).

Tangram - Revista de Educação Matemática, Dourados - MS - v.2 n.1, pp. 21 - 38 (2018) 
Análise de itens sobre sistema monetário brasileiro na Provinha Brasil de Matemática à luz da Teoria dos Campos Conceituais

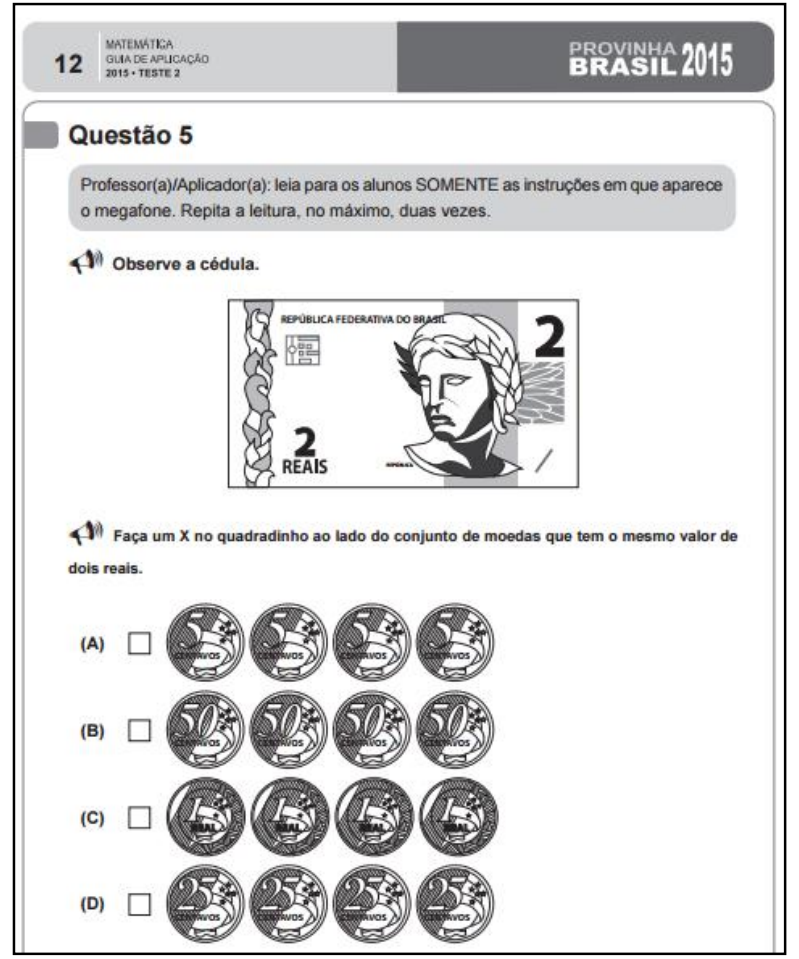

Figura 11 - Teste 2 da Provinha Brasil de 2015 Fonte: Adaptado de Inep (2018).

O problema da figura 11 envolve a composição aditiva de medidas, na qual a operação de adição aplicada à moedas, somando duzentos centavos resulta em uma cédula de dois reais. Percebe-se neste problema o uso do teorema-em-ação "a cada cem centavos tem-se um real", o que indica que também certo conhecimento do sistema de numeração decimal também deve estar desenvolvido para abordar este problema.

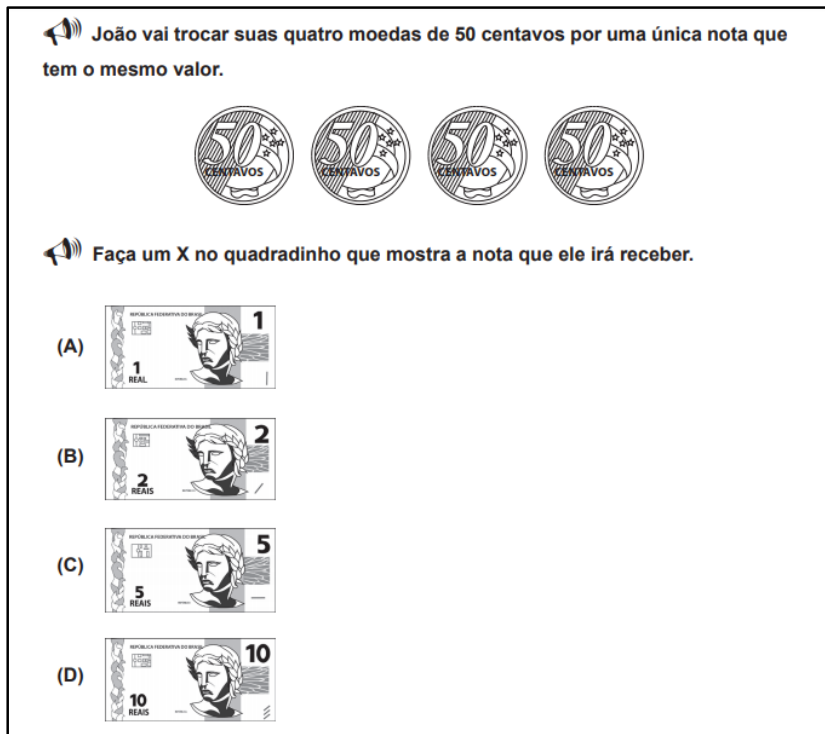

Tangram - Revista de Educação Matemática, Dourados - MS - v.2 n.1, pp. 21 - 38 (2018) 


\section{Análise de itens sobre sistema monetário brasileiro na Provinha Brasil de Matemática à luz da Teoria dos Campos Conceituais}

Figura 12 - Teste 1 da Provinha Brasil de 2016 Fonte: Adaptado de Inep (2018).

Assim como os anteriores, o problema da figura 12 representa uma composição aditiva de medidas. O conceito-em-ação "a cada cem centavos tem-se um real" é requerido. É importante salientar que tal invariante operatório é uma hipótese que assumimos, pois como já foi dito, não realizamos pesquisa com estudantes, mas estamos realizando um exercício de pensar nas possibilidades de pensamento que cada problema potencialmente demanda de estudantes do ciclo de alfabetização, tomando como base os já se sabe na literatura e também a estrutura das questões analisadas.

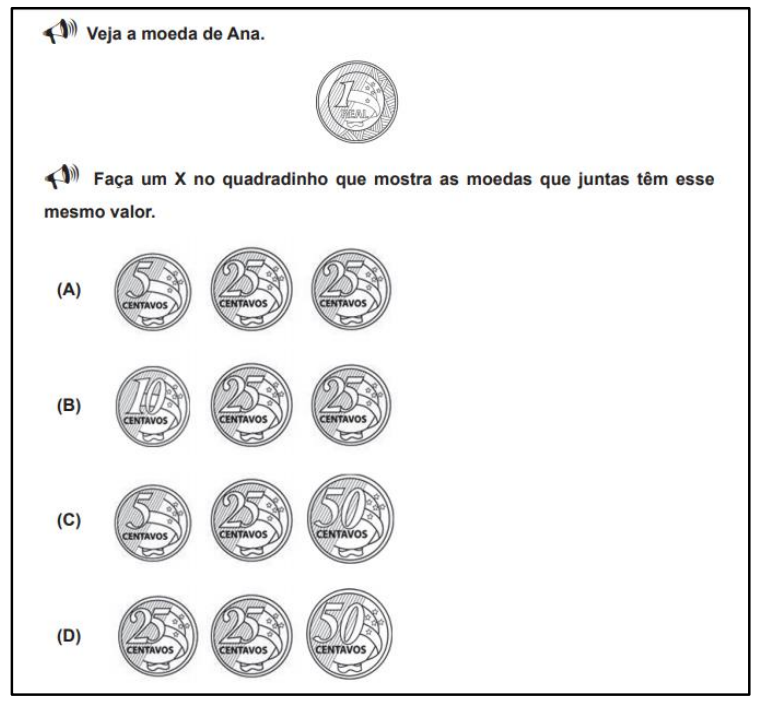

Figura 13 - Teste 2 da Provinha Brasil de 2016 Fonte: Adaptado de Inep (2018).

O problema da figura 13 envolve composição aditiva de medidas, com uso do teorema-em-ação (hipotético) "a cada cem centavos tem-se um real”. Não difere das questões que envolvem a habilidade de relacionar grandezas monetárias presentes em edições anteriores.

\section{Considerações Finais}

Ao analisar situações monetárias que abordam as relações entre cédulas e moedas na Provinha Brasil de Matemática, identificamos a presença de problemas que requerem a habilidade de quantificar, as noções de funcionamento do sistema de numeração decimal e a capacidade de agir em problemas de composição aditiva de medidas. Notamos ausência de Tangram - Revista de Educação Matemática, Dourados - MS - v.2 n.1, pp. 21 - 38 (2018) 


\section{Análise de itens sobre sistema monetário brasileiro na Provinha Brasil de Matemática à luz da Teoria dos Campos Conceituais}

problemas aditivos que envolvam transformação de medidas ou relação entre medidas. Todos os problemas analisados envolvem apenas a composição aditiva de medidas.

Alguns problemas exigem que a criança compreenda o fato de que "a cada cem centavos tem-se um real", e assumimos aqui a hipótese de que este é um conceito-em-ação necessário para o acerto em situações desse tipo. Propomos a investigação da existência deste invariante operatório como um problema de pesquisa de trabalhos futuros.

Com relação ao objetivo do trabalho, "discutir as relações que existem entre as categorias de problemas aditivos propostas por Vergnaud (1985) e os problemas que abordam grandezas monetárias na Provinha Brasil de Matemática", acreditamos tê-lo cumprido na medida em que caracterizamos os tipos de problemas aditivos que se relacionam com as situações monetárias propostas na Provinha Brasil de Matemática.

Para concluir, podemos dizer que a eficácia das estratégias matemática requeridas em problemas monetários da Provinha Brasil depende fortemente do nível de desenvolvimento das estruturas do campo aditivo do estudante.

\section{Referências}

Brasil.(1997) Parâmetros Curriculares Nacionais: Ensino de primeira à quarta série: matemática. Brasília: MEC/SEF.

Castro, Maria Helena Guimarães de. (2000) Sistemas nacionais de avaliação e de informações educacionais. São Paulo em Perspectiva, São Paulo, v.14, n. 1, p.121-128.

Cellard, A. (2008) A análise documental. In: J. Poupart, et al. (Orgs.). A pesquisa qualitativa: enfoques epistemológicos e metodológicos. Petrópolis: Vozes.

Danyluk, Ocsana. (1991) Alfabetização matemática: o cotidiano da vida escolar. Caxias do Sul: EDUCS, 1991.

Inep. (2018) Prova Brasil. Disponível em: <http://provabrasil.inep.gov.br $>$. Acesso em: 27 Set. 2018.

Kamii, C. (1990) A criança e o número: implicações da teoria de Piaget. Editora Papirus, Campinas - SP. Artmed.

May, Tim.(2004) Pesquisa social: questões, métodos e processo. Porto Alegre,

Vergnaud, Gérard. (1985) A criança, a matemática e a realidade: problemas do ensino da matemática na escola elementar. Tradução de Maria Lucia Faria Moro. 3.ed. Curitiba: Editora da UFPR.

Tangram - Revista de Educação Matemática, Dourados - MS - v.2 n.1, pp. 21 - 38 (2018) 
Análise de itens sobre sistema monetário brasileiro na Provinha Brasil de Matemática à luz da Teoria dos Campos Conceituais

Vergnaud, Gérard. (2017)A didática é uma provocação: ela é um desafio. In: GROSSI, Esther Pillar (Org.). Piaget e Vygotsky em Gérard Vergnaud: Teoria dos Campos Conceituais TCC. Coleção Campos Conceituais. Porto Alegre: GEEMPA.

Vergnaud, Gérard. (1990) La théoriedeschampsconceptuels. Recherches em Didactique des Mathématiques, v.10, n.2-3, p.133-170, 1990.

Vergnaud, Gérard.(1997) The nature of mathematical concepts. In Nunes, T. \& Brynt, P. (Eds.) Learning and teaching mathematics, an international perspective. Psychology Press Ltd, Hove (East Sussex).

Enviado:29/09/2018

Aceito:02/12/2018

Tangram - Revista de Educação Matemática, Dourados - MS - v.2 n.1, pp. 21 - 38 (2018) 